\title{
Griscelli syndrome
}

INSERM

\section{Source}

INSERM. (1999). Orphanet: an online rare disease and orphan drug data base. Griscelli syndrome. ORPHA:381

Griscelli syndrome (GS) is a rare cutaneous disease characterized by a silvery-gray sheen of the hair and hypopigmentation of the skin, which can be associated to primary neurological impairment (type 1), immunologic impairment (type 2) or be isolated (type $3)$. 